
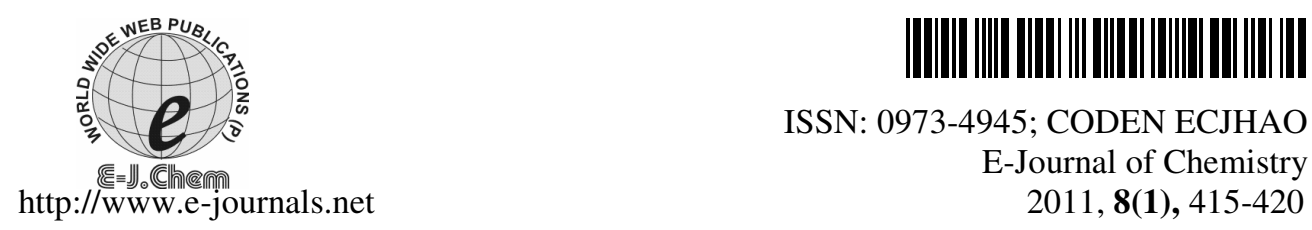

ISSN: 0973-4945; CODEN ECJHAO

E-Journal of Chemistry 2011, 8(1), 415-420

\title{
Synthesis and Structural Studies of First Row Transition Metal Complexes with Tetradentate ONNO Donor Schiff Base Derived from 5-Acetyl 2,4-dihydroxyacetophenone and Ethylenediamine
}

\author{
PULIMAMIDI SARITHA REDDY ${ }^{\S *}$, \\ P.V.ANANTHALAKSHMI ${ }^{\S}$ and V. JAYATYAGARAJU \\ ${ }^{\S}$ Department of Chemistry, University College for Women \\ Osmania University, Hyderabad-500001, Andhra Pradesh, India \\ Department of Chemistry, Addis Ababa University \\ P.O .Box 1176, Addis Ababa, Ethiopia \\ abbareddysaritha@hotmail.com
}

Received 22 April 2010; Accepted 21 May 2010

\begin{abstract}
Cr}(\mathrm{III}), \mathrm{Mn}(\mathrm{II}), \mathrm{Fe}(\mathrm{III}), \mathrm{Co}(\mathrm{II}), \mathrm{Ni}(\mathrm{II}), \mathrm{Cu}(\mathrm{II})$ and $\mathrm{Zn}$ (II) complexes were prepared by template reaction of 5-acetyl 2,4-dihydroxyacetophenone $\left(\mathrm{H}_{2}\right.$ - $\left.\mathrm{ADA}\right)$ and ethylenediamine in the presence of metal ions. The complexes have been characterized on the basis of elemental analyses, conductivity, magnetic moments, infrared and electronic spectral data. The Schiff base binds to metal ions in bis-multidentate ONNO mode leading to two dimensional Schiff base polymers. All the complexes have been assigned octahedral stereochemistry.
\end{abstract}

Keywords: Template reaction, 5-Acetyl 2,4-dihydroxyacetophenone, Ethylenediamine, Bis-multidentate mode, Schiff base polymers.

\section{Introduction}

Schiff bases play an important role in inorganic chemistry as they easily form stable complexes with most transition metal ions ${ }^{1,2}$. The development of the field of bioinorganic chemistry has increased the interest in Schiff base complexes, since it has been recognized that many of these complexes may serve as models for biologically important species. Schiff base metal complexes were investigated for fungicidal, fungistatic, bactericidal and bacteristatic activities $^{3-10}$.

Polynuclear complexes derived from multidentate ligands have documented interesting structural features ${ }^{11-18}$. Literature survey on multidentate ligands having oxygen, nitrogen donor systems reveals an extensive investigation on a number of ONN and ONO donor 
sequences which have resulted in the formation of polynuclear metal chelates ${ }^{19-21}$. A class of ligands with more than one independent chelating sequence substituted on a single phenyl function exemplify bis - chelating ligands which can bind two metal ions simultaneously and form polynuclear complexes ${ }^{22-24}$.

The concept of bis-denticity becomes interesting to study if a variety of symmetric and asymmetric bis-chelating systems are developed and employed in the formation of metal complexes. In view of the importance of multidentate bis-chelating ligands, the investigation on metal complexes of 5- acetyl 2,4-dihydroxyacetophenone $\left(\mathrm{H}_{2}\right.$-ADA ) and a number of its derivatives has been carried out in our laboratories. The present paper deals with the synthesis and characterization of $\mathrm{Cr}(\mathrm{III}), \mathrm{Mn}(\mathrm{II}), \mathrm{Fe}(\mathrm{III}), \mathrm{Co}(\mathrm{II}), \mathrm{Ni}(\mathrm{II}), \mathrm{Cu}(\mathrm{II})$ and $\mathrm{Zn}$ (II) complexes of $\mathrm{H}_{2}$-ADAEN, Schiff base formed by condensation of 5-acetyl 2,4-dihydroxyacetophenone and ethylenediamine.

\section{Experimental}

All the chemicals used were of analar grade. Solvents were dried and distilled before use. Melting points of the complexes were determined on Toshniwal hot stage melting point apparatus and are uncorrected. Carbon, hydrogen and nitrogen analysis was carried out using HERAEUS CHN - Rapid analyser. Chloride analysis was carried out by Mohr's method and metal contents were estimated on a Perkin- Elmer - 2380 atomic absorption spectrometer. The conductivity of metal complexes was measured using a Digisun Digital conductivity meter model D 1909 having dip type cell calibrated with $\mathrm{KCl}$ solution. Mass spectra was recorded in a Perkin-Elmer Hitachi RMU 6L spectrometer. UV Vis - NIR spectra were recorded in solid state on a UV Cary 2390 spectrometer. Magnetic susceptibilities of the complexes were recorded on a Faraday balance (CAHN- 7550-03) at room temperature using $\mathrm{Hg}\left[\mathrm{Co}(\mathrm{NCS})_{4}\right]$ as standard. Diamagnetic correction using Pascal's constants and temperature independent paramagnetic corrections were computed. EPR was recorded on a Jeol SE - 3X Spectrometer at room temperature.

\section{Synthesis of the ligand and metal complexes}

$\mathrm{H}_{2}$-ADAEN, Schiff base formed by the condensation of 5-acetyl 2,4-dihydroxyacetophenone $\left(\mathrm{H}_{2}-\mathrm{ADA}\right)$ and ethylenediamine could be isolated only in the presence of metal ions.

Synthesis of $\mathrm{H}_{2}-A D A$

5-Acetyl 2,4-dihydroxyacetophenone was synthesized by reported procedure $\mathrm{e}^{25,26}$.

\section{Preparation of the complexes}

A general method was adopted for the preparation of all the complexes. To $0.005 \mathrm{~mol}$ $(0.99 \mathrm{~g})$ of 5-acetyl 2,4-dihydroxyacetophenone dissolved in $15 \mathrm{~mL}$ of ethanol, $0.005 \mathrm{~mol}$ of ethylenediamine was added and refluxed for about two hours. The $\mathrm{pH}$ of the solution was adjusted to 8 with the help of dil. $\mathrm{NaOH}$ solution. A yellow solution indicated the formation of the Schiff base. Methanolic solution of the metal chloride was added to the Schiff base solution while stirring. The reaction mixture was refluxed again for four hours. The metal chelates thus separated out were filtered, washed repeatedly with methanol, petroleum ether and diethyl ether and dried in vacuo. The purity of the complexes was tested by TLC using different solvent mixtures. The analytical data and proposed formulae for the complexes are given in Table 1. 
Table 1. Analytical and conductivity data of metal complexes of $\mathrm{H}_{2}-\mathrm{ADAEN}$

\begin{tabular}{cccccc}
\hline \multirow{2}{*}{ Complex } & Analysis & Found & \multicolumn{2}{c}{ (Calcd) $\%$} & \multirow{2}{*}{$\begin{array}{c}\Omega M \\
\text { mho cm }\end{array}$} \\
\cline { 2 - 5 } mol $^{-1}$
\end{tabular}

\section{Results and Discussion}

All the metal complexes except that of zinc are coloured and are stable to air and moisture. They are insoluble in common organic solvents but soluble in DMSO and DMF. They do not melt or decompose until $300{ }^{\circ} \mathrm{C}$. Analytical data shows metal to ligand ratio as $1: 1$ in all the complexes. The analysis suggests the presence of hydroxide ions in $\mathrm{Cr}$ (III) and $\mathrm{Fe}$ (III) complexes. All the complexes possess coordinated water which derives further support from thermal analysis. Low conductance values of these complexes measured in DMSO solutions show that all these complexes are non electrolytes indicating that hydroxide ions in $\mathrm{Cr}(\mathrm{III})$ and $\mathrm{Fe}(\mathrm{III})$ complexes are within the coordination sphere.

\section{Infrared spectra}

IR spectral data of the complexes are given in Table 2. The spectra of metal complexes do not show the characteristic features due to $\mathrm{vNH}_{2}$ (sharp doublet $3300-3200 \mathrm{~cm}^{-1}$ ), $\delta \mathrm{NH}_{2}$ $\left(1600 \mathrm{~cm}^{-1}\right.$; broad) and $\Omega \mathrm{NH}_{2}\left(800-900 \mathrm{~cm}^{-1}\right)$ which are the features of ethylenediamine. The spectra of the complexes also miss the band patterns observed with respect to $\mathrm{H}_{2}-\mathrm{ADA}$, specifically broad strong band due to $v \mathrm{OH}\left(3000-2500 \mathrm{~cm}^{-1}\right)^{27}$ and $v \mathrm{C}=\mathrm{O}\left(1659 \mathrm{~cm}^{-1}\right)^{28}$. Instead the complexes prominently show broad strong bands in the region $3400-3000 \mathrm{~cm}^{-1}$, sharp strong bands in the region $1540-1580 \mathrm{~cm}^{-1}$ and other medium to low intensity bands in the low frequency region. Based on these features it is suggested that the metal complexes are formed by the condensed product between $\mathrm{H}_{2}-\mathrm{ADA}$ and ethylenediamine, which is a two dimensional polymer. The broad bands in the region $3400-3000 \mathrm{~cm}^{-1}$ are attributed to water molecules along with / without hydroxide ions. The variability of band position in the region 1540-1580 $\mathrm{cm}^{-1}$ characteristic of $v \mathrm{C}=\mathrm{N}$ will undoubtedly show its involvement in coordination $^{29}$. The absence of strong band in $1659 \mathrm{~cm}^{-1}$ region is a strong evidence, for the condensation involving both the carbonyl groups with the primary amine function of ethylene diamine.

Table 2. Characteristic infrared frequencies of the complexes of $\mathrm{H}_{2}-\mathrm{ADAEN} \mathrm{cm}{ }^{-1}$

\begin{tabular}{ccccccc}
\hline Compound & $v N H 2$ & $v O H$ & $v C=O$ & $v C=N$ & $v C-O$ & New bands \\
\hline Ligand & $3300-3200$ & $3000-2500$ & 1659 & - & 1256 & - \\
$\mathrm{Cr}(\mathrm{III})$ complex & - & - & - & 1553 & 1287 & $714,550,479$ \\
$\mathrm{Mn}(\mathrm{II})$ complex & - & - & - & 1551 & 1265 & $786,625,492$ \\
$\mathrm{Fe}(\mathrm{III})$ complex & - & - & - & 1558 & 1264 & $744,602,480$ \\
$\mathrm{Co}(\mathrm{II})$ complex & - & - & - & 1559 & 1278 & $783,671,579$ \\
$\mathrm{Ni}(\mathrm{II})$ complex & - & - & - & 1544 & 1261 & $798,688,621$ \\
$\mathrm{Cu}(\mathrm{II})$ complex & - & - & - & 1555 & 1261 & $788,696,616$ \\
$\mathrm{Zn}(\mathrm{II})$ complex & & & & 1560 & 1265 & $784,685,490$ \\
\hline
\end{tabular}


This data will more than prove the existence of condensed product in the complexes. The modification of band structure with positive shift in $v \mathrm{C}-\mathrm{O}$ region corresponding to $\mathrm{H}_{2}$ - ADA is a proof of phenoxide bonding. Non ligand bands observed in the region $590-440$ $\mathrm{cm}^{-1}$ will establish $\mathrm{M}-\mathrm{N}$ and $\mathrm{M}-\mathrm{O}$ bonding ${ }^{30}$. Thus IR data proves the existence of two dimensional Schiff base polymer, binding with ONNO sequence around the metal ions.

\section{Magnetic susceptibilities}

Magnetic susceptibilities of the complexes calculated from room temperature instrumental data and metal ligand stoichiometries are presented in Table 3 . The magnetic moments are in good agreement with the expected high spin configurations. These values show that there are no metal - metal interactions in these complexes. The absence of antiferromagnetic interactions is justified because the metal ions are separated by bulky diamagnetic benzene rings, which efficiently check the spin neutralisation.

Table 3. Magnetic and electronic spectral data of the complexes of $\mathrm{H}_{2}-$ ADAEN

\begin{tabular}{|c|c|c|}
\hline Complex & experimental & Electronic spectral bands \\
\hline $\mathrm{Cr}(\mathrm{III})$ complex & 3.94 & $17200,22700,26000$ \\
\hline Mn(II) complex & 5.95 & 12800,25000 \\
\hline $\mathrm{Fe}(\mathrm{III})$ complex & 5.92 & 12000,24700 \\
\hline Co(II) complex & 4.10 & $8890,17860,21550$ \\
\hline $\mathrm{Ni}(\mathrm{II})$ complex & 2.42 & $8400,10200,19600$ \\
\hline $\mathrm{Cu}(\mathrm{II})$ complex & 1.62 & $12000,12987,14084,17391,21147$ \\
\hline
\end{tabular}

\section{Electronic spectra}

The electronic spectrum of $\mathrm{Cr}(\mathrm{III})$ shows three intense bands, characterised in the descending order of frequency to represent the transitions ${ }^{4} \mathrm{~A}_{2} \rightarrow{ }^{4} \mathrm{~T}_{1}(\mathrm{P}) ;{ }^{4} \mathrm{~A}_{2} \rightarrow{ }^{4} \mathrm{~T}_{1}(\mathrm{~F})$ and ${ }^{4} \mathrm{~A}_{2} \rightarrow{ }^{4} \mathrm{~T}_{2}(\mathrm{~F})$.

$\mathrm{Mn}(\mathrm{II})$ and $\mathrm{Fe}(\mathrm{III})$ complexes show a number of electronic spectral bands, attributed to a number of spin forbidden transitions involving ${ }^{6} \mathrm{~A}_{1}$ ground state and several higher energy quartet states in accordance with octahedral geometry.

Electronic spectrum of Co(II) complex shows bands, assigned to ${ }^{4} \mathrm{~T}_{1}(\mathrm{~F}) \rightarrow{ }^{4} \mathrm{~T}_{2}(\mathrm{~F}),{ }^{4} \mathrm{~T}_{1}(\mathrm{~F})$ $\rightarrow{ }^{4} \mathrm{~A}_{2}(\mathrm{~F})$ and ${ }^{4} \mathrm{~T}_{1}(\mathrm{~F}) \rightarrow{ }^{4} \mathrm{~T}_{1}(\mathrm{P})$ transitions respectively which are in support of octahedral arrangement of binding centres around the metal ion. The electronic spectrum of $\mathrm{Ni}$ (II) complex is assigned to ${ }^{3} \mathrm{~A}_{2} \rightarrow{ }^{3} \mathrm{~T}_{2},{ }^{3} \mathrm{~A}_{2} \rightarrow{ }^{3} \mathrm{~T}_{1}(\mathrm{~F})$ and ${ }^{3} \mathrm{~A}_{2} \rightarrow{ }^{3} \mathrm{~T}_{1}(\mathrm{P})$ transitions for octahedral geometry.

The spectrum of $\mathrm{Cu}(\mathrm{II})$ complex shows medium intensity multiple bands, assigned to various transitions involving ${ }^{2} \mathrm{~B}_{1}$ ground term and ${ }^{2} \mathrm{~B}_{2},{ }^{2} \mathrm{~A}_{2}$ and ${ }^{2} \mathrm{E}$ higher energy terms due to distorted octahedral geometry.

\section{EPR spectrum of copper(II) complex}

The EPR spectrum of copper(II) complex at liquid nitrogen temperature has been evaluated to give $\mathrm{g}_{\mathrm{II}}$ and $\mathrm{g}_{\perp}$ values as 2.199 and 2.083. The $\mathrm{g}$ values indicate a distorted octahedral geometry. Since $\mathrm{gII}>\mathrm{g}_{\perp}>2.0023$, the ground state ${ }^{31}$ of $\mathrm{Cu}(\mathrm{II})$ is $\mathrm{d}_{\mathrm{x}}{ }^{2} \mathrm{y}^{2}$, and the symmetry is tetragonally distorted octahedral.

\section{Antimicrobial activity}

Preliminary studies on the bactericidal properties of the metal complexes indicate promising activity against Staphylococcus aureus. Detailed studies are in progress. 


\section{Conclusion}

Based on the positions of $\mathrm{vNH}_{2}, \mathrm{vC}=\mathrm{N}$ and $v \mathrm{C}-\mathrm{O}$ (phenolic) in the spectra of the complexes of $\mathrm{H}_{2}$ - ADAEN, it is concluded that $\mathrm{H}_{2}$-ADA and ethylenediamine undergo 1:1 condensation and bind to metal ions in bis-multidentate ONNO mode leading to two dimensional Schiff base polymers. On the basis of analytical, thermal, conductivity, magnetic and spectral data, octahedral geometries have been proposed for all the complexes. (Figure 1)

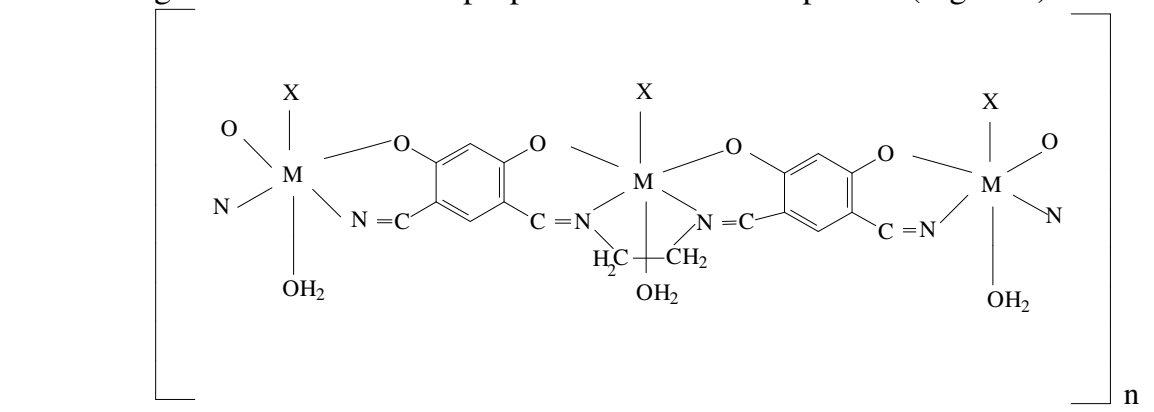

$-\mathrm{M}=\mathrm{Ce}(\mathrm{III}), \mathrm{Fe}(\mathrm{III}), \mathrm{ML}(\mathrm{OH}) \mathrm{H}_{2} \mathrm{O} ; \mathrm{X}=\mathrm{OH}, \mathrm{M}=\mathrm{Mn}(\mathrm{III}), \mathrm{Co}(\mathrm{II}), \mathrm{Ni}(\mathrm{II}), \mathrm{Cu}(\mathrm{II}), \mathrm{Zn}(\mathrm{II}), \mathrm{ML}_{2} \mathrm{H}_{2} \mathrm{O} ; \mathrm{X}=\mathrm{H}_{2} \mathrm{O}$

Figure 1. Complexes of $\mathrm{H}_{2}-\mathrm{ADAEN}$

Despite multidenticity of the ligands and polymeric nature of the complexes, normal high spin equivalent magnetic moments have been exhibited by the complexes. Lack of metal metal interactions is another notable feature. The absence of antiferromagnetic interactions is justified because the consecutive metal ions in the two dimensional polymeric network are separated by bulky diamagnetic benzene rings which efficiently check spin neutralisation.

\section{References}

1. Shallaby A M, Mustafa M and Moussa, Spectrochim Acta, 1989, 40A, 999.

2. Mustafa M, IbrahimK M and Moussa, Trans Met Chem., 1984, 9, 243.

3. Rao D S, GanorkarM C, Reddy C S and John V J, Curr Sci.,1980, 49, 511.

4. Garg R K and Sharma L M, J Indian Chem Soc., 1992, 69, 703.

5. Rai B K, Choudhary P, Rana S and Sahi P, Oriental J Chem., 2007, 23(1), 291-296.

6. Adel Z, Sonbato, Ashraf A and El.Bindary, Trans Met Chem., 1992, 17, 66-70.

7. Savanini L, Chiasserini L, Gaeta A and Pellerano C, Biorg Med Chem., 2002,10, 2193.

8. Rama Rao N, Jayatyagaraju V, Venkateshwara Rao P and Ganorkar M C, National Academy Sci Lett India, 1985, 8, 343-346.

9. Arya K K and Ahmad S, Oriental J Chem., 2007, 23(1), 239-44.

10. Babu Rao C, Ganapaty S, Ramalingam P, Varun D, Prabhakaran C and Sridar S, Acta Ciencia Indica Chem., 2006, 32(4), 363 - 365.

11. Masahiro, Mikuriya and Mika Fukuya, Bull Chem Soc Japan, 1996, 69, 679-683.

12. Aneetha Halikedkar, Chepuri R K and Zacharias, J Chem Soc. Dalton Trans., 1997, 10, 1697.

13. Jose C, Vites and Lyman M M, Coord Chem Rev., 1995, 138, 15.

14. Mikuniya M, Nakadera K and Tokii T, Inorg Chim Acta., 1992, 194, 129.

15. Uday Mukhopadhyay and Debashis Ray, Indian J Chem., 2001, 40A, 228.

16. Mohod R B, Wasu R V and Aswar A S, J.Indian Chem Soc., 2001,78, 34.

17. Hankare P P, Patil R K, Chavan S S, Jagtap A H and Battase P S, Indian J Chem., 2001, 40A, 1326. 
18. Lallan Mishra and Ragini Sinha, Indian J Chem., 2000, 39A, 1131.

19. Anantha Lakshmi P V, Saritha Reddy P and Jayatyaga Raju V, Spectrochimica Acta Part A, 2009, 74, 52- 57.

20. Dutta R L and Ray R K, J Indian Chem Soc., 1983, 60, 185.

21. Chohan, Hussain Z, Pervez and Humayun, Synth Reac Inorg Met -Org Chem., 1993, 23(7), 1061.

22. Hirokaju, Miyoshi, Hiroki, Mihara and Seiichikanda, Bull Chem Soc Japan, 1996, 69(7), 993.

23. Rao T R, Lingaiah P, Sirdeshmukh L and Mehdi S, J Indian Chem Soc., 1989, 66, 826.

24. Fox M A and McCarty P J, Adv Mater., 1991, 3, 386.

25. Anjaneyulu A S R and Prasad A V R and Reddy D S, Curr Sci., 1979, 48(7), 300-301.

26. Balasubramanian A and Sankaran P, Indian J Chem., 1981, 20B, 989.

27. Syamal A and Kale K S, Indian J Chem., 1978, 16A, 46-48.

28. Verma J K and Verma G S P, Indian J Chem., 1964, 26A, 37.

29. Tatwawadi S V, Singh A P and Narang K K, Indian J Chem., 1982, 21A, 644.

30. Jorgensen C K, Absorption Spectra and Chemical Bonding in Complexes Pergamon Publications, 1962, 2, 92.

31. Yudhir Sharma S, Pandey H N and Pavan Mathur, Polyhedron, 1994, 13(22), 3111-17. 


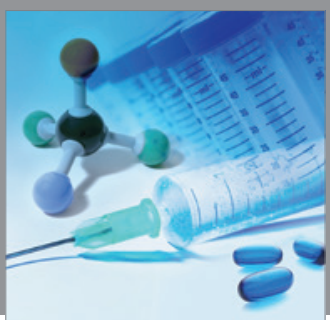

International Journal of

Medicinal Chemistry

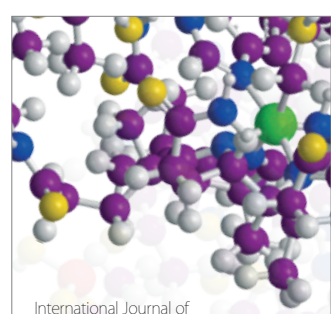

Carbohydrate Chemistry

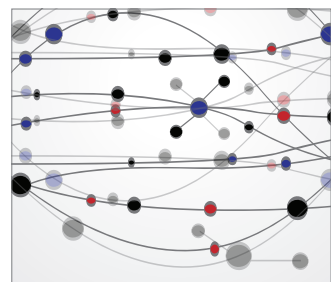

The Scientific World Journal
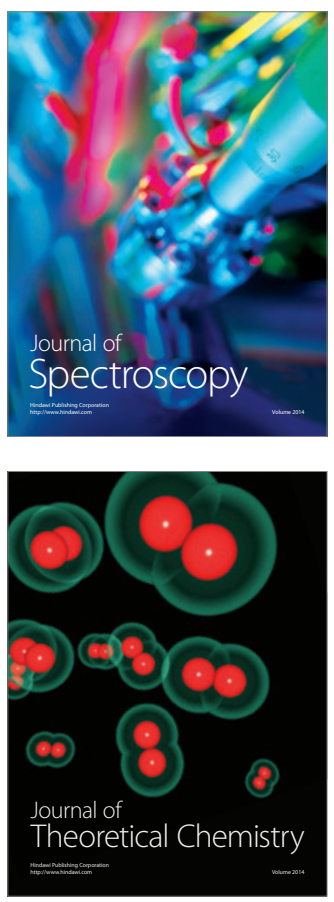
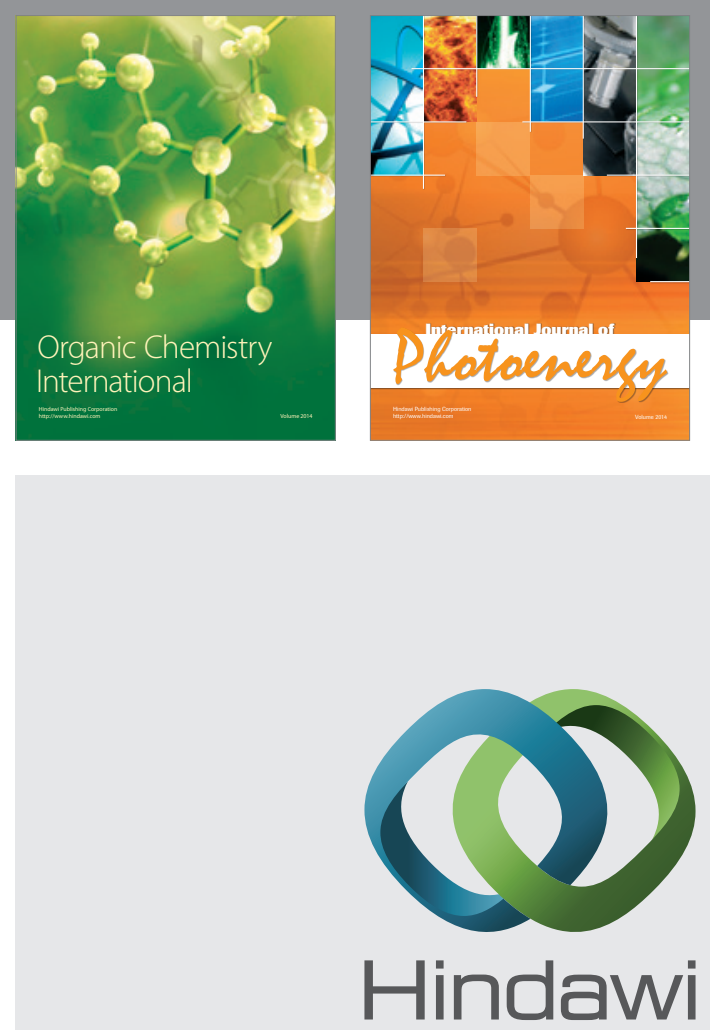

Submit your manuscripts at

http://www.hindawi.com
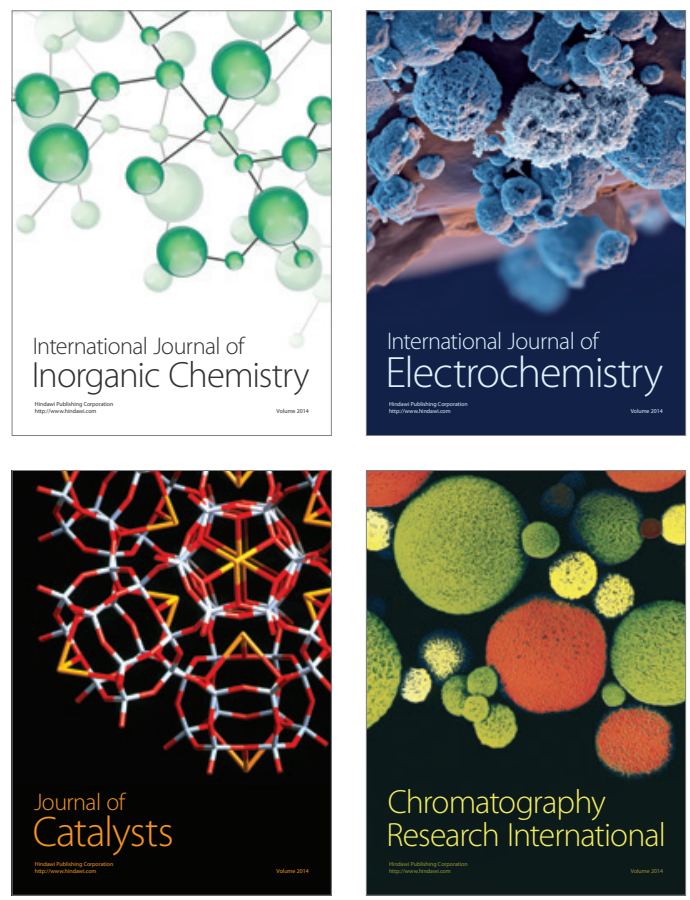
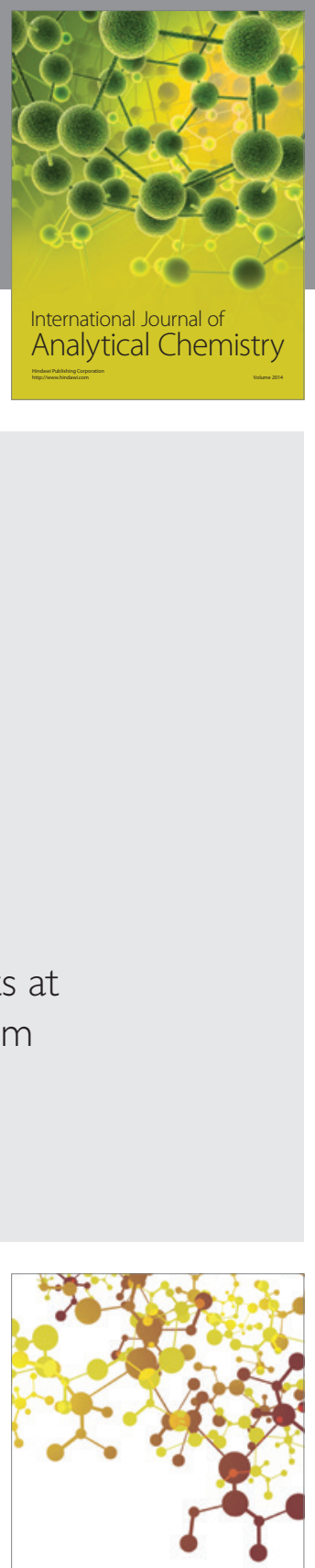

Journal of

Applied Chemistry
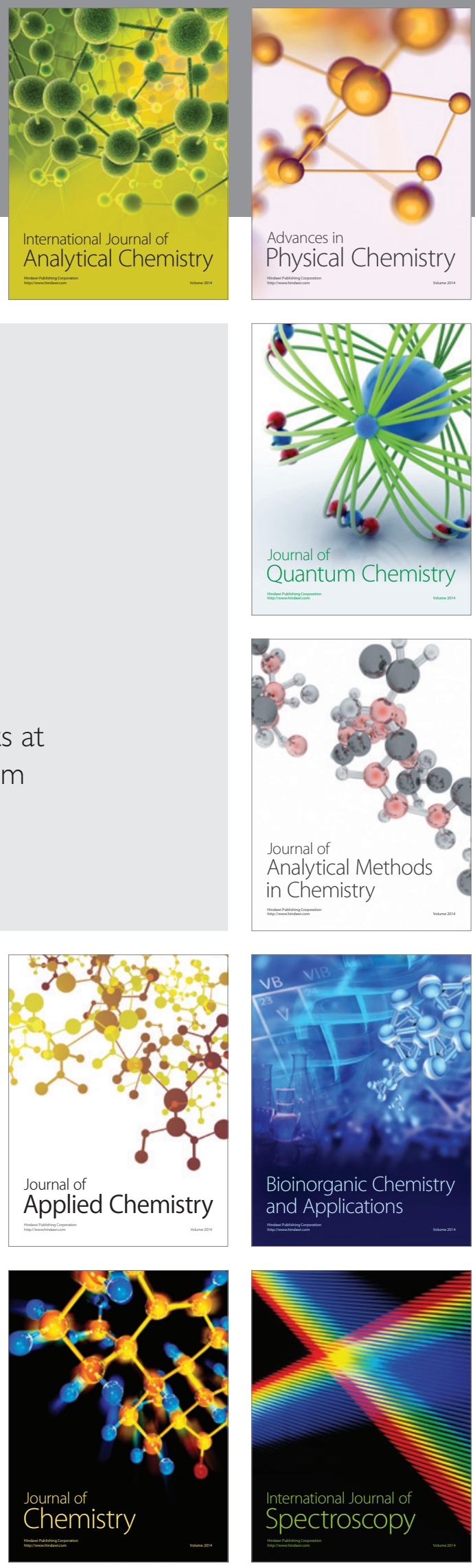